\title{
Organização do ensino da linguagem escrita: contribuições da teoria histórico- cultural
}

\author{
The organization of the teaching of the written \\ language: contributions from the historical and \\ cultural theory
}

\section{Organisation de l'enseignement du langage écrit:contributions de la théorie historique-culturelle}

\author{
Patricia Cristina Formaggi CAVALEIRO
}

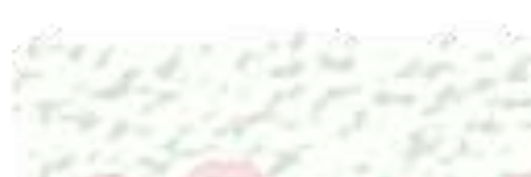

Marta Sueli de Faria SFORNI

\section{RESUMO}

Os resultados das avaliações da Educação Básica realizadas pelo Ministério da Educação (MEC) tem revelado que o desempenho dos estudantes em língua portuguesa tem sido muito aquém ao esperado. Esse fato indica a necessidade de se buscar práticas pedagógicas que tenham impactos mais positivos na aprendizagem dos estudantes. Neste sentido, no presente texto é apresentada parte de uma pesquisa desenvolvida com $\sigma$ objetivo investigar modos de organização do ensino da linguagem escritá que promovam a aprendizagem e o desenvolvimento dos estudantes, conforme potencial formativo do ensino defendido pela teoria históricocultural. Para isso, foi realizado um experimento didático formativo no qual foram trabalhados conteúdos da linguagem escrita durante um período de três meses, em uma turma de $3^{a}$ série do Ensino Fundamental de uma escola pública do Estado do Paraná. A coleta de dados foi efetuada por meio de observações, registro de atividades e videogravações. No presente texto são apresentados alguns episódios de ensino sobre o conteúdo pontuação. A análise do experimento permitiu observar que a aprendizagem dos estudantes é favorecida quando são contempladas atividades que envolvem reflexão e que exigem deles a elaboração ativa do conhecimento. Para isso situações-problema envolvendo o conteúdo demonstraram ser mobilizadoras de ações mentais necessárias à aprendizagem consciente do aluno. Verificou-se que as atividades de ensino precisam ser planejadas pelo professor de modo que requeira do aluno a atenção diretamente dirigida ao objeto de aprendizagem. Identificou-se que a explicitação verbal dos alunos sobre suas hipóteses pode ser um instrumento norteador das ações do 
professor, pois possibilita que este acompanhe o tipo de atividade mental que o aluno está realizando com o conteúdo.

Palavras-chave: aprendizagem; linguagem escrita; ensino; teoria histórico-cultural.

\begin{abstract}
Fundamental Education's evaluation results produced by the Brazilian Ministry of Education revealed that students' performance in Portuguese has not been up to standard. Pedagogical practices with more positive impacts in students' learning are highly required. Current essay comprises a section of a research which investigates the organization in the teaching of the written language that would trigger learning and students' development according to learning formation potential established by the historical and cultural theory: A formation didactic experiment was undertaken in which subject matters on the written language were undertaken during three months in a third grade classroom of a government primary school in the state of Paraná, Brazil. Data collection was done by observations, reports of activities and video-recordings. Some teáching episodes on punctuation in Portuguese are given in current text. Analysis of the experiment showed that students' learning is enhanced when activities that involve reflection and requires the active elaboration of knowledge are taken into account. Situations-problem on the subject matter triggered the required mental activities for the student's conscious learning. It has also been verified that teaching activities should be planned by the teacher so that the students would focus their attention on the object of learning. Student's verbal explicitness on their hypotheses may be a guiding-toof for the teacher's activities. In fact the teacher will thus follow the type of mental activity that the students are undertaken with the subject matter.
\end{abstract}

Index terms: Learning; written language; teaching; historical and cultural theory.

\title{
RÉSUMÉ
}

Les résultats des évaluations de l'Éducation Basique realisées par le MEC (Ministère del'éducation) ont démontré que la performance des étudiants en langue portugaise est loin d'être satisfaisante. Ce fait indique la nécessité de chercher des pratiques pédagogiques qui ont des impacts plus positifs sur l'apprentissage des élèves. Dans ce sens, ce texte présente une recherche développée dans le but d'enquêter des modes d'organisation de l'enseignement du langage écrit qui promeuvent l'apprentissage et leur développement, selon le potentiel formateur de l'enseignement soutenu par 
la théorie historique-culturelle. Pour cela une expérience didactique formative a été réalisée dans laquelle ont été travaillé des contenus du langage écrit pendant trois mois dans une classe de CM1 (primaire) dans une école publique de l'État du Paraná. La collecte de données a été effectuée à partir d'observations, d'activités ainsi qu'à partir d'enregistrements de vidéos. Ce texte présente également quelques enregistrements concernant l'enseignement de ponctuation. L'analyse de l'expérience a permis d'observer que l'apprentissage est favorisé quand y sont contemplées des activités qui impliquent leur réflexion en exigeant le dévelopemment actif de la connaissance des élèves. Des situations-problème concernant le contenu ont démontré la mobilisation d'actions mentales nécessaires à l'apprentissage conscient de l'élève. On a vérifié que les activités doivent être organisées par le professeur, de façon à retenir l'attention de l'élève vers l'objet d'étude. Finalement on a constaté que l'explicitation des élèves à propos de leurs hypothèses peut être un instrument entraîneur des actions du professeur car il permet à celuli-ci d'accompagner le genre d'activité mentale avec lequel l'élève travaille.

Mots-clés: Apprentissage; langage écrit; enseignement; théorie historique-cuturelle.

\section{Introdução}

É bastante conhecida a afirmação de Vigotski ${ }^{1}$ (2001) de que o ensino adequadamente organizado resulta em desenvolvimento dos estudantes. Se por um lado essa concepção teórica aponta para uma valorização da escola, por outro traz consigo um problema a ser-resotvido: eomo organizar o ensino de modo que venha, de fat $\sigma$, promover o desenvolvimento dos alunos inseridos nesse processo?

Movidos por essa problemática passamos a refletir sobre a organização do ensino da linguagem escrita com vistas a essa formação. A preocupação com a aprendizagem da língua materna em sua modalidade escrita decorre do fato de os conteúdos de todas as áreas do conhecimento estar codificados, predominantemente, nesse tipo de linguagem. Assim, a

Optamos por utilizar neste texto a grafia Vigotski, conforme está grafado nas obras que estamos utilizando como principais referencias, mas preservaremos, nas referencias bibliográficas, a grafia própria de cada edição. 
falta de domínio da linguagem escrita, seja na sua codificação, seja na decodificação, constitui-se em uma barreira para a apropriação dos conteúdos das várias disciplinas escolares.

Tal fato torna-se preocupante à medida que se observa o baixo desempenho dos alunos brasileiros nas avaliações de Língua Portuguesa realizadas pelo Ministério da Educação, como o Programa Internacional de Avaliação de Alunos (PISA) do ano de 2000 (BRASIL, 2001), do Sistema Nacional de Avaliação da Educação Básica (SAEB) (BRASIL, 2003-2004) e da Prova Brasil (BRASIL, 2007).

O desempenho dos estudantes brasileiros nessas avaliações indica a necessidade de se rever os pressupostos que òrientaram nas últimas décaldas o ensino da língua materna nas séries iniciais do ensino fundamental, bem como de se buscar práticas pedagógicas que tenham impactos mais positivos na aprendizagem dos estudantes.

Com essa finalidade, realizamos uma pesquisa que teve como objetivo investigar modos de organização do ensino e analisar indícios de aprendizagem da linguagem escrita decorrentes dessa organização. Pará isso, buscamos suporte teórico em conceitos da abordagem históricocultural.

\section{Procedimentos metodológicos}

Para que uma investigação dessa natureza fosse possível, foi necessário organizar experimentos formativos para que pudéssemos analisar o processo de elaboração do pensamento dos alunos rumo à apropriação dos conteúdos. Tomamos como referência o modelo de experimentos formativos propostos por Davidov (1988). Para este autor, "esse método apóia-se na organização e reorganização de novos programas de educação e ensino de procedimentos para sua efetivação" (DAVIDOV, 1988, p. 196). A opção pelo uso do experimento formativo neste estudo decorreu das possibilidades 
investigativas que a intervenção do pesquisador no fenômeno proporciona, sendo que "O método do experimento formativo caracteriza-se pela intervenção ativa do pesquisador nos processos mentais que ele estuda" (DAVIDOV, 1988, p. 196). A principal característica do experimento formativo é que não se busca com ele atuar naquilo que já está desenvolvido e formado no sujeito, mas planejar ações que promovam novas estruturas psíquicas e investigar o caminho para que isso se efetive. Ou seja, esse método permite "[...] estudar simultaneamente as condições e as leis da gênese da correspondente nova formação psíquica" (DAVIDOV, 1988, p. 196). Assim, parafraseando Davidov, podemos dizer que o objetivo da nossa pesquisa foi organizar atividades por meio de experimentos didáticos com a intenção de "estudar as condições e as leis de origem" de uma relação teórica da criança com a escrita.

As intervenções ocorreram no período de março a julho de 2008. Os encontros ocorreram em dois dias da semana, com duração de uma hora e meia a duas horas cada dia, totalizando 26 dias de intervenção. As aulas foram filmadas, o que possibilitou um exame mais detalhado das ações do§ alunos.

\section{Sujeitos}

O experimento didático foi realizado em uma turma de terceira série do ensino fundamental do sistema público de ensino de um município do Estado do Paraná. A turma era composta por 24 alunos, com idade regular para a série.

\section{Procedimentos para a realização das atividades}

Para a realização das atividades, solicitávamos que a turma se organizasse em grupos composto por quatro alunos para a resolução de 
situações-problema que envolviam o conteúdo em pauta. Os grupos eram formados conforme a afinidade entre os integrantes.

Considerávamos que essa forma de organização da sala poderia favorecer o aparecimento de conflitos teóricos e discussões entre os alunos na resolução das atividades propostas, já que se esperava que as situaçõesproblema desencadeassem necessidades de realização de ações para atingir um objetivo e, no grupo, a ação de cada um precisava ser discutida para que chegassem a uma ação comum.

Após as discussões preliminares nos pequenos grupos, passávamos as discussões coletivas. Nesse momento, era possível a discussão e a interação entre todos, sendo que cada grupo já tinha uma possibilidadè de resposta formulada anteriormente. O quadro 1 (anexo) demonstra a organização dos pequenos e do grande grupo, bem como a interação entre sujeitos e grupos.

Rivina (1996, p. 139) preconiza que,

[...] numerosos estudos já haviam demonstrado que as atividades comunitárias são não apenas um meio eficaz de aprender a resolver este ou aquele problema, mas são também capazes de contribuir, em muito, para o desenvolvimentò das operações e das ações cognitivas na criança.

Para analisar indícios de ações mentais durante a realização dos experimentos, foram buscadas contribuições de autores como Davidov (1988), Semenova (1996), Rubtsov (1996), Rivina (1996), Sforni (2004), além de autores clássicos da abordagem histórico-cultural como Vigotski (2001, 2007) e Leontiev (1983, 2004).

\section{Análise dos episódios de ensino}

Vários conteúdos foram trabalhados ao longo do semestre, relataremos apenas alguns episódios do experimento de ensino sobre pontuação. A pesquisadora, que é professora em outra escola do mesmo 
município da escola campo de pesquisa, assumiu a condução das aulas durante a realização de todo o experimento. Portanto, no relato dos episódios optamos por identificá-la como professora. Uma das tarefas dos alunos consistia em resolver, por meio do uso da pontuação, o seguinte problema:

Um homem ia viajar, mas chegou atrasado à rodoviária e o ônibus já estava saindo. Então ele gritou para o motorista não prosseguir, pois ele gostaria de viajar naquele ônibus. Então ele escreveu a seguinte frase num papel: "Não espere"

A professora pediu aos alunos que pontuassem a frase de forma que o motorista entendesse que era para ele parar o ônibus e esperar o homem.

A problematização apresentou-se como fator decisiva na mobilização de ações mentais, e segundo Rubtsov (1996, p. 133), “[...] o conceito de problema de aprendizagem está estreitamente ligado ao de ação cognitiva, a qual se caracteriza principalmente pelo modo de analisar um objeto".

A maneira com que foram organizadas e desenvolvidas as atividades de pontuação tinha como objetivo desencadear a reflexão entre os alunos, de modo quèe-eles não ficassem vinculados ao acerto ou erro da frase, mas que analisassem a pontuação como um objeto de aprendizagem. A intenção era a de que eles pudessem perceber o conceito de pontuação como atributo relativo à gramática, mais precisamente à suplementação semântica. Para isso, a necessidade de pontuar as frases era mobilizada pela adequação do sentido do texto. A pontuação das frases era norteada pela sintaxe, visto que os pontos eram utilizados de forma a dispor e relacionar os elementos da frase estruturalmente almejando produzir o sentido estabelecido no contexto em questão, nesse caso, adequar a função semântica. 
Após a pontuação das frases pelos grupos, estas foram afixadas no quadro-negro e a professora conduziu a análise de cada frase pontuada a fim de verificar qual estava registrada de forma mais adequada para garantir que a mensagem fosse compreendida conforme a intenção do autor. A necessidade desse momento de intervenção do adulto nas reflexões dos alunos é corroborada por Rubtsov, para quem a cooperação entre as crianças é fundamental, mas é necessário que a criança tenha "[...] o adulto como parceiro para adquirir diversos elementos da ação, tais como a correção ou a avaliação, sobre as quais ainda não tem domínio” (RUBTSOV, 1996, p. 134).

L 1 - P - Qual foi o grupo que consegui escrever de forma que fizesse o motorista parar o ônibus e esperar?

L 2 - P - O grupo da Tha colocou assim: "Não. espere!"

L 3 -P - Turma, está certo?

L 4 - Seb - Não, pois o homem está admirado - (O aluno lê a frase com a entonação correta da pontuação).

L 5 - P - Então, mas será que mesmo com esse tipo de ponto, o motorista conseguiu entender que era para ele parar? - Veja bem turma, é para o ônibus fazer o que?

L 6 - Seb - Parar

L 7 - Alunos- Parar

L 8 - P - E esse ponto aqui (apontando para o ponto de exclamação do final da frase) serve para dizer o que? Não quer dizer que o homem estava desesperado, emocionado, aflito por que o ônibus estava saindo?

L 9 - Seb: É daí sim.

Nesse episódio, a fala do aluno Seb (linha L 4) demonstra que seu conceito de ponto de exclamação se restringe ao uso em situações de expressão de sentimentos de admiração e alegria, e por isso, em sua concepção, o ponto de exclamação não pode ser usado para transmitir a 
mensagem estabelecida pela atividade, que era fazer com que o motorista parasse o ônibus.

Nesse processo de elaboração conceitual do aluno, a mediação do adulto apresenta-se como requisito indispensável (L 5 e L 8), neste caso ela não se limitou a afirmar se estava certo ou errado, mas suscitou no aluno uma ação mental voltada para a análise da frase. Na L 9, o aluno demonstra ter compreendido que o ponto de exclamação também poderia ser usado para pontuar a frase em questão, o que demonstra que a mediação docente se constituiu em um elemento fundamental para a reflexão e análise por parte do escolar.

L 10 - Jes - Olha profi, aquele ali, tá errado: "Não espere."

L 11 - Dan - É, tá errado. Porque não colocaram o ponto ali no meio daí não dá para o motorista entender.

L 12 - P - Como se lê essa frase?

L 13 - Não espere.

L 14 - P - O que o motorista entenderia com essa frase pontuada dessa forma?

L 15 - Seb - que não era para ele esperar.

L 16-P-E o que temos que mudar para o motorista entender que é para ele esperar?

L 17 - Dan - colocar um ponto no meio.

L 18 - P - Ale, o que temos que colocar para ele entender?

L 19 - Brun 2 - Pode ser exclamação no meio da frase e depois um ponto final. Daí, a frase fica assim: "Não! espere."

L 20 -P - Agora vamos ler (É feita a leitura coletiva da frase). Deu para entender?

L 21 - Alunos - Deu

L 22 - P - O que estava faltando era o ponto de exclamação, e agora o que falta?

L 23 - Dan - Letra maiúscula. 
$\mathrm{Na} \mathrm{L} \mathrm{10,} \mathrm{a} \mathrm{aluna} \mathrm{realiza} \mathrm{a} \mathrm{análise} \mathrm{da} \mathrm{frase} \mathrm{por} \mathrm{si} \mathrm{mesma,} \mathrm{afirmando}$ estar equivocado o uso da pontuação. $\mathrm{Na}$ L 11, o aluno também realiza a análise e justifica porque está errado. A ação de ambos indica que eles estabeleceram uma relação com o conteúdo do texto e a pontuação da frase diferente daquela estabelecida inicialmente, pois em suas observações sinalizam que estão atentos à finalidade da pontuação. Suas falas evidenciam o exercício do pensamento teórico, já que nelas está pressuposta a função simbólica desses elementos gráficos. Nesse caso, é possível verificar a elaboração de uma inferência pautada no conceito de pontuação; trata-se de um raciocínio que tem origem na frase apresentada, que é uma situação particular, mas caminha em direção à generalização do conteúdở.

As linhas 15 e 17 mostram a análise do aluno conduzida pela mediação docente realizada nas linhas 14 e 16 . Na linha 19, evidencia-se a generalização da aluna, pois ela demonstra que outro ponto também pode ser usado nessa situação.

Após a análise das frases pontuadas pelos grupos, a professora lançou outro problema: a mesma frase deveria ser pontuada de forma que transmitisse outra mensagem. A atividade consistia na seguinte situạçãoproblema:

Do primeiro banco do ônibus, uma mulher gritou que não era para o motorista esperar, pois aquele homem era um louco.

Depois da exposição da situação-problema, pediu-se aos alunos que pontuassem a frase "Não espere" de forma que o motorista entendesse que não era para ele esperar e sim prosseguir.

De acordo com Sforni (2004), a modificação das situaçõesproblema, que nesse caso se refere à pontuação de diferentes frases, possibilita aos alunos extrair as características essenciais que determinam o 
conteúdo e a estrutura do conceito. A alteração no sentido da frase, mantendo-se a mesma grafia, modificou os parâmetros de referência dos alunos, desencadeando uma dinâmica em que as relações essenciais seriam adequar os pontos de acordo com a semântica. A tarefa de pontuar a mesma frase de forma diferente possibilita comparar dois objetos que aparentemente são os mesmos, porém as relações entre conteúdo e objeto precisam ser modificadas. Semenova (1996, p. 163) pondera que esse fato torna possível descrever uma fórmula que é comum à relação objetoconteúdo. No caso da atividade de pontuação, a "fórmula" pode ser comparada às generalizações realizadas na busca do princípio de pontuação das frases, já que o mesmo conteúdo aplicàdo ao mesmo objeto precisa valer-se de relações diferenciadas.

Essa nova etapa da atividade visava conduzir os alunos a uma generalização, haja vista que o mesmo conteúdo deveria ser usado em uma situação diferente, e para sua realização não bastava somente reproduzir 0 conteúdo da atividade, sendo preciso que o aluno realizasse uma análise, já que precisava pontuar a frase de maneira adequada à nova mensagem proposta.

Desse modo, a necessidade do aluno foi motivada para o desempenho de ações que envolvem reflexão e análise.

L 24 P-Agora vamos ver qual grupo conseguiu fazer o motorista entender que não era para ele esperar.

L 25 P- Vamos ver o grupo da Isa. Esse grupo escreveu: Não espere!

L 26 Seb- Ah, certinho, ele entendeu, certíssimo.

L 27 P-Vamos para o próximo grupo. Esse grupo escreveu: Não espere.

L 28 Brun 2- ficou errada.

L 29 P-Porque está errada? 
L 30 Brun 2- Por que sim, esse ponto aí, esse ponto... Tem que ficar igual aquela lá (Não espere!)

\section{31 P-Então vamos ver que diferença tem.}

L 32 Fizemos a leitura das duas frases. Não espere! Não espere.

L 33 P-agora me diga Brun, qual a diferença?

L 34 Brun 2- A diferença é que lá falou admirado.

L 35 Jes - E na outra não falou normal.

L 36 P-Então, mas nas duas o motorista entendeu que era para ele não esperar?

L 37 Brun 2- É deu sim, tá certo.

L 38 P-Então turma, deu para entender?

L 39 Alunos - Sim

L 40 Seb- Então pode deixar as duas assim que estão certinhas.

Novamente partiu-se da necessidade de pontuar a frase de forma que transmitisse a mensagem (L 24); essa necessidade foi o motivo da aprendizagem dos alunos. Na L 25, provocamos a análise da frase pelos alunos e pedimos para que eles analisassem se a frase estava pontuada da forma correta.

$\mathrm{Na} L$ 26, o aluno concluiu que estava correta, poís permitia ao motorista entender a mensagem. Com sua resposta, o aluno quer dizer que os pontos estavam dispostos na frase de forma correta, pois eles cumpriram a função de adequar a frase para transmitir a mensagem estabelecida.

$\mathrm{Na}$ L 27, novamente a professora provocou a análise; na L 28, a aluna conclui por meio da análise comparativa entre o conteúdo de pontuação e sua utilização que a frase está pontuada errada, e desse modo, os pontos precisam ser adequados à intenção da comunicação. Na L 29, a aluna foi questionada pela professora: "Por que está errada?", e por meio da comparação com outra frase em que a pontuação está sendo usada de forma correta a aluna analisa, compara e diz que o ponto precisa ficar igual ao da 
frase pontuada corretamente (L 30). Nesse momento, a mediação docente (L 32) conduziu a aluna à reflexão por meio de análise comparativa entre dois elementos: a frase que a aluna se refere como correta e a frase que a pontuação precisa ser adequada. Na L 34, a aluna analisa uma frase, e na L 35 , outra aluna analisa outra frase, e nesse momento a mediação do adulto é primordial, pois leva as alunas a sintetizarem a análise comparativa realizada entre ambas as frases (L 36). A aluna demonstra ter conseguido realizar a análise por meio da comparação entre as duas frases pontuadas de forma diferente. A ação mental da aluna por meio de uma reflexão caminhou rumo à generalização do conteúdo, já que ela conseguiu reconhecê-lo em duas situações diferentes ( L 37). Na L 38, nos dirigimos à turma para ver se conseguiram alcançar a mesma compreensão da aluná e a turma reponde de forma positiva (L 39), com a confirmação de outro aluno de que "estão certinhas" ( L 40).

O episódio abaixo demonstra a análise da frase pontuada por outro grupo.

L 41 P-Vamos ler a frase deste grupo

L 42 Não, espere.

L 43 Seb- tá errado.

$\mathrm{L} 45$ P-vou ler de novo e você vai ver se é possível o motorista entender que é para ele continuar.

L 46 Seb- ah, não vou falar mais também.

L 47 P-Mas, Seb, a professora não está dizendo se está certo ou errado, eu quero que você pense junto comigo, pra ver se está certo ou errado.

L 48 Seb- Então não tem nenhum ponto no meio.

L 49 P-Onde?

L 50 Seb- No Não.

L 51 A professora apaga o ponto do meio e lê a frase, "Não espere."

L 52 Wel- Seb- Isso agora ficou certo, certinho. 


\section{53 P-Então leia para ver se ficou correto.}

L 54 Alunos- ficou sim, deu pra entender.

$\mathrm{Na} L \mathrm{4}$ 46, o aluno mostrou-se revoltado, "não vou falar mais," por que esperava a confirmação se o seu posicionamento estava certo ou errado e a mediadora respondeu chamando-lhe a confrontar sua resposta com uma análise; nesse momento, o espírito de reflexão presente na fala da professora "eu quero que você pense junto comigo," se constitui na condição primordial para provocar a ação mental do aluno, que em seguida analisa a frase junto com a professora e conclui que está correto.

O posicionamento da professora na $L 47$ demonstra a sua intenção de atuar na zona de desenvolvimento proximal do aluno, já que ela está conduzindo, provocando ações mentais mediante as respostas dos alunos, e desse modo, atuando no nível de desempenho com os conteúdos que os alunos ainda não são capazes de dominar sozinhos.

No final da realização das atividades, como uma maneira de sintetizar de forma sistemática as ações dos alunos, a professora provocou questionamentos para concluir a atividade.

L 55 P- O que dá pra gente pensar disso tudo que aconteceu hoje? Se a gentecolocar os pontos na frase de qualquer jeito fica correto?

L 56 Alunos- Não

L 57 P-então a gente precisa fazer o que?

L 58 Wel- falar para depois fazer e colocar os pontos.

L 59 P-Seb, posso colocar qualquer ponto?

L 60 Seb- não primeiro tem que pensar.

L $61 P$ - Ah, então primeiro tem que pensar o que a gente vai falar para depois saber os pontos que vai usar?

L 62 P-É isso turma?

L 63 Alunos- Sim. 
$\mathrm{Na}$ L 55, a professora suscita os alunos a sintetizar o que aconteceu, isto é, fazer o processo inverso da análise, identificar o que era comum (geral) a todas as situações de pontuação. Ao mesmo tempo em que a professora exige que os alunos sintetizem e concluam, mais uma vez a sua mediação mostra-se primordial nesse processo, porque ela conduz a ação mental do aluno: "Se a gente colocar os pontos na frase de qualquer jeito, fica correto?" Quando o aluno responde “não", novamente a professora (L 57) exige que ele justifique a resposta. A insistência para que os alunos justifiquem suas respostas pauta-se no princípio de que a linguagem não apenas expressa o pensamento, mas também permite sua organização; assim, o momento de expressar verbalmente a ação realizada é importânte na aprendizagem dos alunos.

A resposta do aluno "falar para depois fazer e colocar os pontos" demonstra a necessidade do pensamento empírico para a formação do pensamento teórico, e também mostra a aprendizagem do aluno nèsse processo de elaboração. Quando a professora pergunta ao aluno o que tem que fazer para pontuar uma frase, o aluno responde (L 60), "primeiro, tem que pensar", nessa fala do aluno está contida a necessidade da elaboração ativa, de ações mentais, para que sua aprendizagem se efetive. Desse modo, ao mesmo tempo em que executa a atividade, seus processos mentais são desenvolvidos. Além de esse aluno aprender um conteúdo, ele aprendeu também um modo de ação que lhe dá autonomia para futuras produções textuais, ou seja, a sua ação com a atividade estendeu-se para além da resolução da tarefa específica.

\section{Considerações finais}

Práticas de ensino centradas na transmissão de conceitos prontos mediante atividades de memorização e repetição de conhecimentos pouco contribuem para o desenvolvimento psíquico do aluno. Por outro lado, o 
abandono do conhecimento sistematizado e a livre atuação dos alunos com a linguagem escrita, que têm marcado as atuais práticas pedagógicas, têm contribuído para a produção de um alarmante fracasso escolar. Nesse sentido, em nossa pesquisa concluímos que no processo de ensino é preciso viabilizar situações de aprendizagem que tenham como foco central os conceitos científicos, mas que visem à elaboração ativa desses conhecimentos por parte dos estudantes. Para a organização de um ensino que promova a aprendizagem e o desenvolvimento dos alunos não basta somente que haja a transmissão do conteúdo; muito mais que isso, é preciso organizar essa transmissão de modo propício ao desempenho de uma atividade, como explica Leontiev $(1983,2004)$.

$\mathrm{O}$ desenvolvimento das funções psíquicas envolve o trabalho com o pensamento teórico e com a elaboração ativa dos conteúdos, ou seja, envolve a reflexão, a análise e a generalização. Aprendizagem que se evidencia quando o aluno sabe usar os conteúdos como ferramentas do seu pensamento.

Neste sentido, por meio da análise qualitativa das respostas do§ alunos durante as atividades de ensino é possível verificar que essa forma de organizar o ensino foi favorável à mobilização das funções psíquicas dos alunos rumo à apropriação ativa dos conhecimentos.

As atividades de pontuação elaboradas durante a pesquisa previam a elaboração coletiva por parte dos alunos de modo que eles pudessem levantar hipóteses, analisar as situações e identificar as semelhanças e diferenças entre as frases pontuadas por eles em cada grupo. Essa dinâmica permitiu a geração de conflitos em torno do conteúdo, e por esse motivo as atividades foram realizadas em um processo de elaboração coletiva entre alunos e o adulto como mediador das decisões tomadas pelos grupos no momento de pontuar.

Durante o desenvolvimento das atividades no decorrer da pesquisa, foi possível observar uma estrutura de elaboração do conhecimento que 
partia do nível interpsíquico para o intrapsíquico, conforme exposto no quadro 3 (anexo).

Neste sentido, o ensino assume papel primordial no desenvolvimento do aluno e o professor assume papel decisivo no processo de ensino e aprendizagem. Segundo Vigotski (2001), a relação entre o pedagogo e a criança configura-se em uma forma de colaboração no processo de desenvolvimento das funções psicológicas superiores.

Por meio desse trabalho, foi possível também verificar que o postulado de Vigotski (2001) de que "o bom ensino é aquele que se adianta ao desenvolvimento" ainda precisa ser mais investigado, abrangendo os vários conteúdos que compõe o currículo escòlar.

\section{Referências bibliográficas}

BRASIL. Ministério da Educação. Programa Internacional de Avaliação de Alunos-PISA: PISA 2000 - Relatório Nacional. Brasília, DF, 2001. Disponível em: <http://www.inep.gov.br/download/internacional/pisa/PISA2000.pdf>. Acesso em: 03 out. 2008.

\section{$2003-$} Ministério da Educação. Resultados do SAEB. Brasília, DF, 〈http://www.inep.gov.br/download/saeb/2004/resultados/BRASIL.pdf.> Acesso em: 07 nov. 2008.

Ministério da Educação. Sistema de Avaliações do Ensino Brasileiro-Prova Brasil. Brasília, DF, 2007. Disponível em: <http://provabrasil.inep.gov.br/> Acesso em: 11 de out. 2008.

DAVIDOV. V. V.. La enseñanza escolar y el desarrollo psíquico. Madrid: Progresso, 1998.

LEONTIEV, A. N.. Actividad, conciencia, personalidad. Habana: Pueblo y Educación, 1983.

O desenvolvimento do psiquismo. São Paulo: Centauro, 2004. 
RIVINA. I.. A organização de atividades coletivas e o desenvolvimento cognitivo em crianças pequenas. In: GARNIER, C.; BERNARDEZ, N.; ULANOVSKAYA, I. Após Vygotski e Piaget: perspectiva social e construtivista. Escolas russa e ocidental. Tradução Eunice Gruman. Porto Alegre: Artes Médicas, 1996. p. 138-150.

RUBTSOV. V.. A atividade de aprendizado e os problemas referentes à formação do pensamento teórico dos escolares. In: GARNIER, C.; BERNARDEZ, N.; ULANOVSKAYA, I. Após Vygotski e Piaget: perspectiva social e construtivista. Escolas russa e ocidental. Tradução Eunice Gruman. Porto Alegre: Artes Médicas, 1996. p. 129-137.

SEMENOVA. M.. A formação teórica e científica do pensamento dos escolares. In: GARNIER, C.; BERNARDEZ, N.; ULANOVSKAYA, I. Após Vygotski e Piaget: perspectiva social e construtivista. Escolas russa e ocidental. Tradução Eunice Gruman. Porto Álegre: Artes Médicas, 1996, p. 160-168.

SFORNI. M. S. F.. Aprendizagem conceitual e organização do ensino: contribuições da teoria da atividade. Araraquara: Editora JM, 2004.

VIGOTSKI. L. S.. A construção do pensamento e da linguagem. São Paulo: Martins Fontes, 2001.

A formação social da mente: o desenvolvimento dos processos superiores. São Paulo: Martins Fontes, 2007..

\section{Autoras:}

Profa. Ms. Patricia Cristina Formaggi Cavaleiro

Rede Municipal de Ensino de Mandaguari

Contato: patyformaggi@yahoo.com.br

Profa. Dra. Marta Sueli de Faria Sforni

Universidade Estadual de Maringá

Contato:martasforni@uol.com.br

Texto recebido em março de 2011.

Texto aprovado para publicação em junho de 2011. 


\section{Como citar este texto:}

CAVALEIRO, P. C. F.; SFORNI, M. S. de F.. Organização do ensino da linguagem escrita: contribuições da teoria histórico- cultural.. Revista Acolhendo a Alfabetização nos Países de Língua Portuguesa, Brasil, São Paulo, volume 1, $\mathrm{n}^{\circ} .11$, pp. 127 - 145, Set.. 2011. Disponível em: <http://www.acoalfaplp.net>.

\section{Anexo}

Quadro 01 - Elaboração do conhecimento do nível interpsíquico para o intrapsíquico

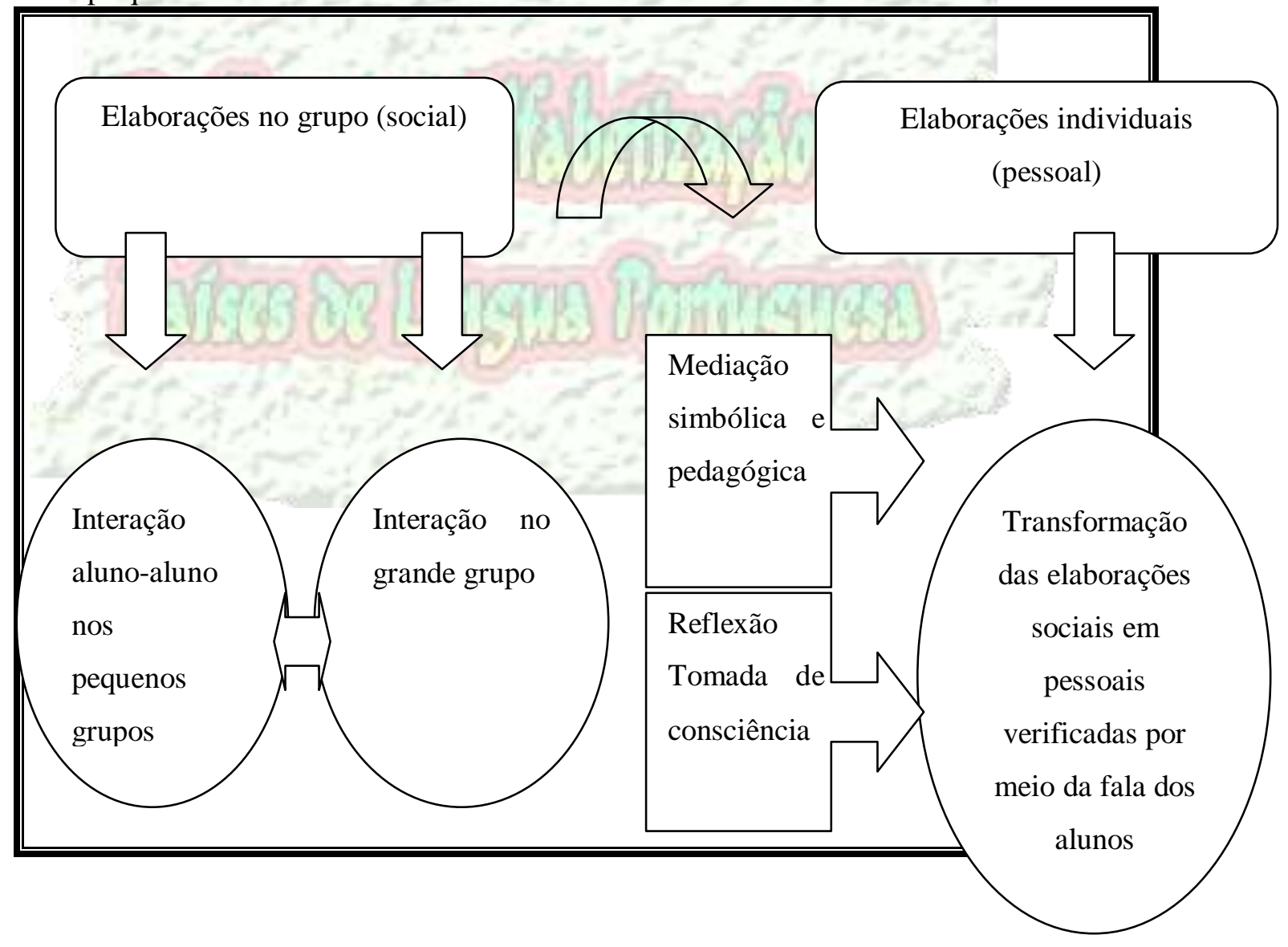

